\title{
UNA GLOSA RECONSTRUCTIVA IDEAL. EL ANTIGUO CIPRES BARROCO DE LA CATEDRAL DE MORELIA
}

\author{
Manuel González GalváN
}

El distinguido investigador e historiador Oscar Mazín Gómez, en su libro Entre dos Majestades, subtitulado El obispo y la Iglesia del Gran Michoacán ante las reformas borbónicas, 1758-1772. Publicado por el Colegio de Michoacán, 1987, Zamora, Mich. Aparte del importante tema estudiado y desarrollado magníficamente, en el Apéndice Documental, nos dá a conocer como doctumento número $\mathrm{XI}$, una interesantísima descripción que el retablista Isidoro Vicente de Balbás, dirige al cabildo de la catedral vallisoletana en la segunda mitad del sigo XVIII. Esta descripción complementa los planos o "mapas", que el artista propone para realizar los retablos mayor y de los Reyes en la misma catedral.

Ahora bien, el propio investigador Oscar Mazín, al encabezar el documento, se confundió con la referencia del retablo al titularle:

Descripción para el Retablo de Reyes de la catedral de Valladolid de Michoacán.*

Esto ha ocasionado desconcierto en otros historiadores e investigadores cuando de interpretar se trata la reseña en cuestión, como veremos a continuación pues, como es sabido, los retablos llamados de los Reyes, en nuestro mundo hispánico era común se colocaran en los ábsides catedralicios.

Pero, en el caso de Morelia con ábside plano, la descripción no encaja bien, pues se habla de "cuatro frentes" o caras y, si acaso, en este ábside se podría contar con tres; la del fondo y las dos laterales.

Así veamos un significativo párrafo al respecto escrito por Jorge Alberto Manrique en un artículo publicado en el periódico La Jornada, el martes 8 de septiembre de 1987, titulado "Catedrales desnudas: Morelia". En él intuye que algo no ajusta cuando el retablo "cubriría los tres lados de la cuadrada capilla de los Reyes".

* En conversación personal tenida con Oscar Mazín, así lo reconoció con justa honestidad académica, al grado de que en próxima nueva publicación suya en la revista oficial del Colegio de Michoacán, Relaciones núm. 34, 1988, el título habrá de ser otro, así cuim la interpretación informativa. 
Pero citemos con más amplitud el párrafo ya que además Manrique nos proporciona en él una somera pero necesaria y cumplida información:

Varios documentos, especialmente una larga carta de Isidoro Vicente de Balbás (o Balvás) al cabildo de Valladolid, establecen como el seguro autor del proyecto del retablo de los Reyes a ese artista Isidoro Vicente, hijo adoptivo de Jerónimo de Balbás, autor del ciprés, altar del Perdón y altar de los Reyes en la catedral de México, había realizado obras tan importantes para la fecha de la carta (leída en cabildo en mayo de 1768) como los retablos de Santa Prisca de Taxco y los retablos del Sagrario Metropolitano.

En la carta descubierta por Mazín, Isidoro Vicente describe someramente el retablo de los Reyes que se comprometía a hacer; éste cubriría los tres lados de la cuadrada capilla de los Reyes, y ostentaría pilastras estípites monumentales en los ángulos (lo cual lo relaciona con el de su padre en México) y dos 'camarines' o templetes superpuestos en la parte central.

Otros documentos muestran que el retablo sólo se construiría en 1773, ya muerto el obispo Sánchez de Tagle, siguiendo el modelo de Isidoro Vicente de Balbás, pero por mano de Francisco Gudiño, maestro queretano. El cabildo prefirió ese proyecto al de otro queretano, Mariano de las Casas.

Ahora bien si pasamos de la comprensión descriptiva del retablo, a su representación gráfica, la dificultad se acentúa, pues el discurso escrito deja con mayor libertad trabajar a la imaginación, en tanto que el concepto captado plásticamente implica menor posibilidad de variación (lám. 1).

A este reto se enfrentó el arquitecto Hugo Valdéz con el intento de captar objetivamente en un plano de levantamiento lo que el texto balbasiano sugiere, pero al insistirse en la planimetría considerada para el retablo de los Reyes, también la elocuencia gráfica no resulta corresponder debidamente a una composición clara y lógica, presentándose tan solo como el despliegue de un repertorio de elementos formales reseñados, pese al meritorio esfuerzo por acercarse o comprender el mensaje compositivo arquitectónico y estilístico de la época.

Frente a tales dificultades, y dado el gran interés histórico y artístico contenidos en el texto de Balbás, intentaremos ahora, por nuestra cuenta, encontrar una interpretación que a nuestro entender y juicio personal se aproxime lo más posible a la intención del proyecto balbasiano, a lo que fue su posterior realidad y a lo que, por su desafortunada desaparición, ahora tan solo nos queda tratar de imaginar en ideal reconstrucción.

Para esto creemos que lo más apropiado es realizar una cuidadosa glosa del documento con un comentario particular a cada uno de los diez párrafos principales que lo constituyen. De esta manera, a continuación 
transcribimos íntegro y de corrido el texto con sus párrafos numerados para enseguida ofrecer el comentario.

\title{
DOCUMENTO
}

\author{
APENDICE XI \\ DESCRIPCION PARA EL RETABLO DE REYES \\ DE LA CATEDRAL DE VALLADOLID DE MICHOACÁN
}

El presente mapa hecho por don Isidoro Vicente de Babbás tiene de alto dieciséis varas y su ancho por todos sus cuatro lados es el de cuatro varas en cuadro. Contiene muchas estatuas de santos reinos y serafines; logra una especial colocación y determinación de sus miembros, como lo manifiesta su alzado. Lleva cuatro puertas; la una podrá servir de entrada para el manejo del primero camarín y para el segundo, así como para su remate; las otras tres podrán servir de alacenas con el mediano campo que ofrece el espacio de la regular distribución de los seguros para su firmeza.

Tiene en sus ángulos determinada subida para su uso, la cual se puede regular y ver por su planta. Esta no tiene peralte alguno de escalones, que si los llevara sería dilatar más el espacio en que se halla determinada y embarazaría lo interno del primero y segundo camarín que no es necesario. ${ }^{2}$

Lleva en las cuatro frente de su primero y segundo cuerpo los pabellones que ofrece su diseño, que en caso de oscurecer sus interiores podrán omitirse y elevarse para estorbar esta reflexión. ${ }^{3}$

Tiene cuatro estípites grandes en sus ángulos, sobre los que rematan encima de su coronación los cuatro doctores o los santos que el venerable señor deán y cabildo tuvieren por conveniente. ${ }^{4}$

En el primer camarín reciben sus cuatro arcos, sirviéndoles de impostas las ocho coronaciones de los estípites que guarnecen el empilastrado de sus muros, sobre las que se ven figuradas ocho frontis que tienen su arranque de la corona que cubre el banquillo de dichas cornisas, sobre los que se miran adornados cada uno con dos reinos, con atributos o insignias de cada uno de los santos patriarcas que en dicho lugar se ven figurados, los cuales van opuestos a los arbotantes que se gozan por sus lados. ${ }^{5}$

De bastante follaje y gustosa talla, síguense correlativamente los mismos. disminuidos, especialmente en la formación de sus ocho medios estípites que se hallan inmediatos al segundo camarín de El Salvador. Éstos están adornados con medallas, serafines y cortejos de caprichosa idea. ${ }^{6}$

Al pie de los dichos están en cada uno de ellos, dos mancebos con espigas de oro alusivas al divino sacramento. Sobre las coronaciones de los dichos se dejan ver los siete príncipes y para completar los ocho lugares se podrá colocar el santo ángel custodio? 
Síguese el remate adornado con la misma fachada que muestra su delineación en sus cuatro lados de ángeles, serafines y adornos de talla caprichosa formando una graciosa tarjeta en la que están las armas de san Pedro; en las tres de su mismo tenor se puede diferenciar con las armas de la Iglesia o con las que parezca más del agrado del venerable señor deán y cabildo. Remata sobre dicha tarjeta el triunfo de la fe, con el acompañado de ocho ángeles con palmas y ramos de oliva. ${ }^{8}$

Los cuatro depósitos omito relacionarlos, por lo muy patente que se dejan ver en su delineación, pues en el se muestra lo claro, vistoso y agradable de su construcción. ${ }^{9}$

En lo que dice aprecio, me remito a la exposición que tengo presentada al muy ilustre y venerable señor deán y rabildo, dudando el manejo que pueda haber en esa ciudad con los operarios y costos de maderas, el que una vez informado de todo, haré lo que sea del agrado de dichos señores sin ningún perjuicio mío. Por tanto lo firmé. ${ }^{10}$

Isidoro Vicente de Balbás

\section{GLOSA}

' Desde el primer párrafo caemos en la cuenta de que este retablo no puede ser el de tipo usual, adosado a muros ya que, con sus dieciséis varas de alto por cuatro de ancho y en cuadrado, tiene una estrecha y esbelta proporción de uno a cuatro lados, por tanto debe mostrarse exento y libre en sus cuatro caras las que, fundidas en su gran esbeltez, hacen que éste sea, necesariamente; iun ciprés!

La abundancia de esculturas, especialmente de "reinos" o arcángeles, asî como de serafines, es una característica muy del barroco estípite, en especial en la obra tanto de Jerónimo como de Isidoro Vicente de Balbás. Además, el que no se mencionen pinturas, confirma este sentido escultórico y volumétrico de la obra, que rechaza la planimetría picțórica.

Las cuatro puertas dichas, de las que sólo una daría acceso a los camarines superpuestos y las tres restante podrían servir como parvas alacenas alojadas entre los apoyos o "seguros para su firmeza", lo que nos indica la necesidad de conservar una armónica simetría perimetral y también es de suponerse por esto que tales puertas deberían ubicarse angularinente y en "chaflán", puesto que el centro de los cuatro frentes correspondería a los altares.

${ }^{2}$ Este párrafo resulta el más oscuro y difícil de glosar ya que en su comprensión, prácticamenete queda definida la forma de la planta. Es aventurada cualquier suposición 0 aseveración al respecto, no obstante nos

"Aunque Isidoro Vicente firma, de Balvás, preferimos referirnos a su apellido con la ortografía del de su padre: Balbás. 
DOI: http://dx.doi.org/10.22201/iie.18703062e.1988.59.1403

\section{LAMINAS E ILUSTRACIONES}




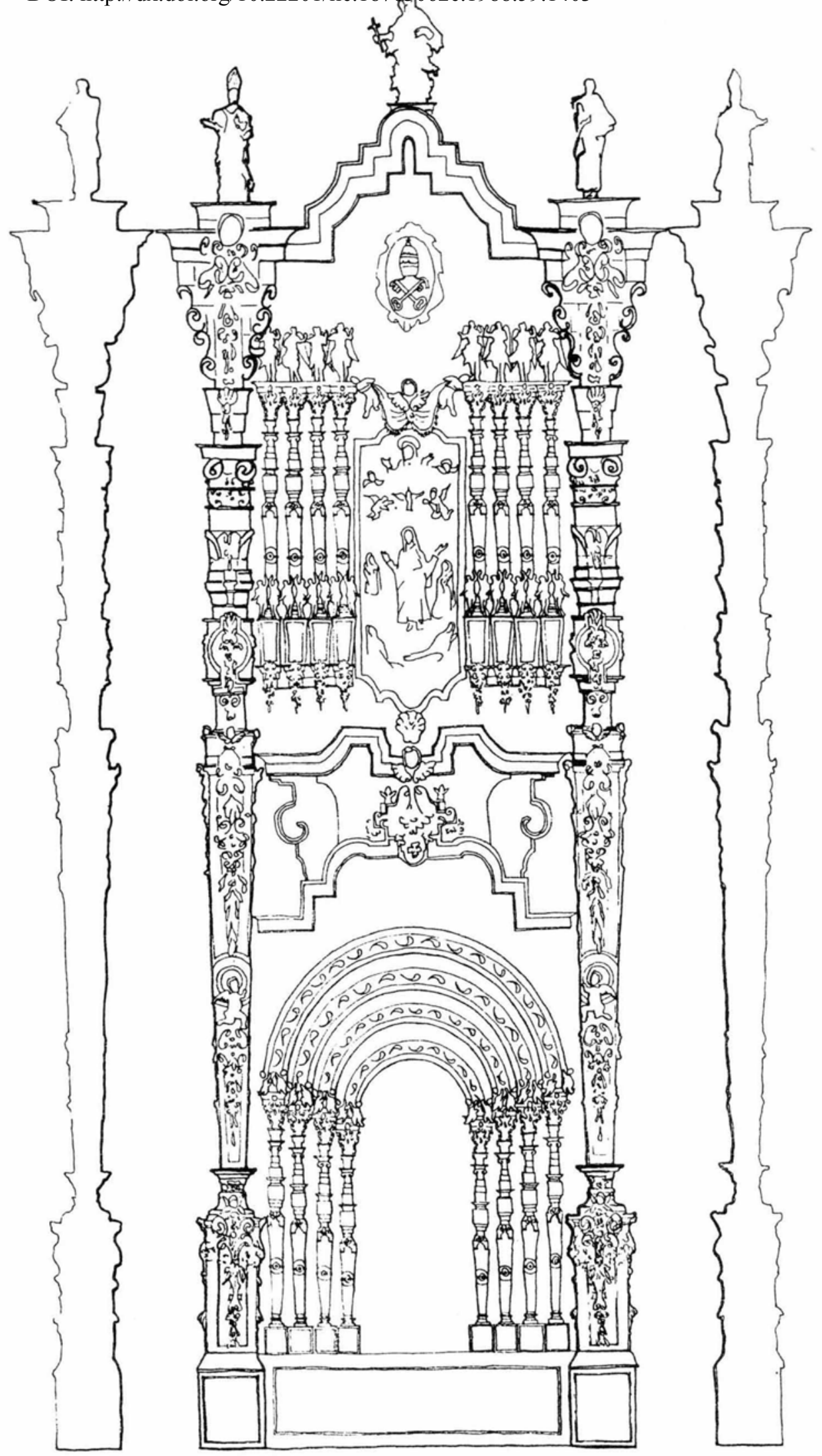


Lámina 1. Levantamiento reconstructivo del retablo de los Reyes. Dibujo realizado por el arquitecto Hugo Valdéz en 1987. Se tomó del libro Entre dos majestades, de Oscar Mazín Gómez. El Colegio de Michoacán, 1987. 
DOI: http://dx.doi.org/10.22201/iie.18703062e.1988.59.1403

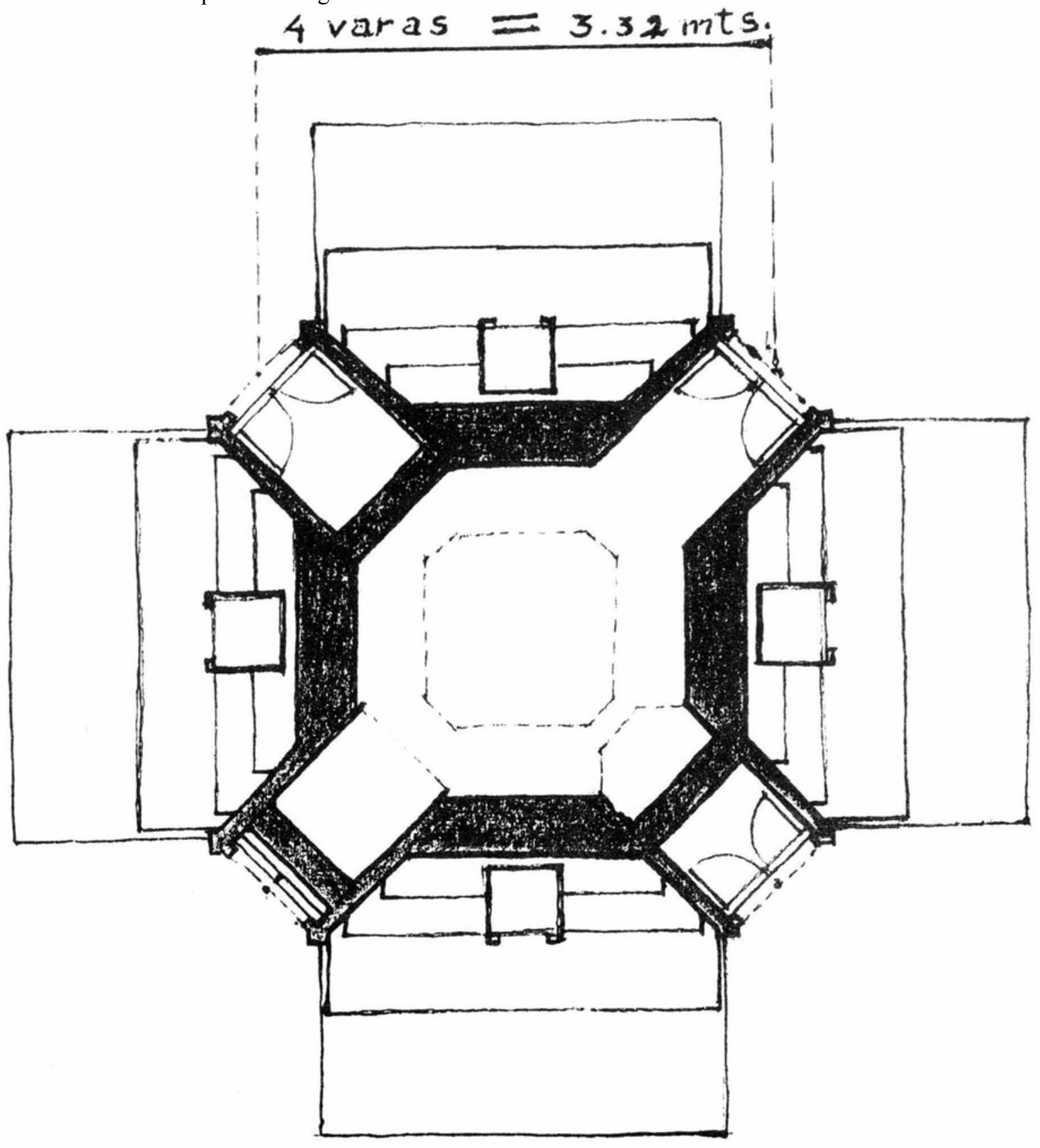


Lámina 2. Planta reconstructiva ideal del ciprés barroco de la catedral de Valladolid (Morelia), Michoacán. Aunque de difícil y dudosa interpretación, por lo poco claro del párrafo que en el documento glosado se refiere a este desplante, la disposición se ofrece como una posible aproximación al original, con alguna también posible variante en los tramos angulares que se considera "podrán servir de alacenas". Interpretación, esquema y dibujo de Manuel González Galván. 


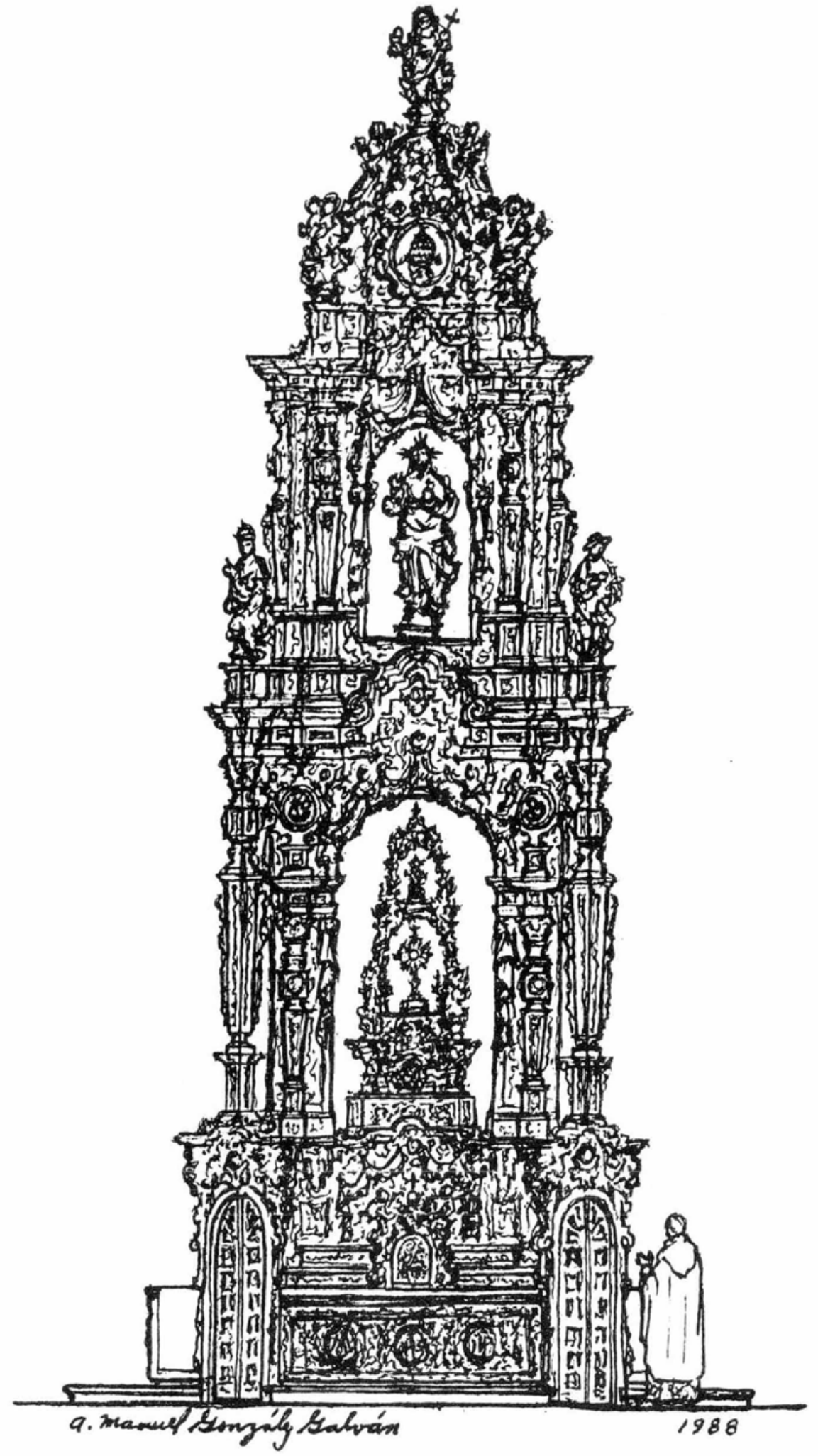


Lámina 3. Elevación o alzado del ciprés barroco de la catedral de Valladolid (Morelia), Michoacán. Reconstrucción ideal conforme a lo que sugiere la descripción del proyecto hecho por Isidoro Vicente de Balbás, presentada y leída al cabildo en mayo de 1768. Sin llegarse a un detallamiento exhaustivo sí es factible imaginar con relativa veracidad, aunque sin precisión, las formas de proporción, composición estructura y decoración que esta obra tuvo, hasta donde la descripción de su propio autor lo permite y conforme a la glosa del documento que este alzado o levantamiento pretende ilustrar. Interpretación y dibujo de Manuel González Galván. 
DOI: http://dx.doi.org/10.22201/iie.18703062e.1988.59.1403

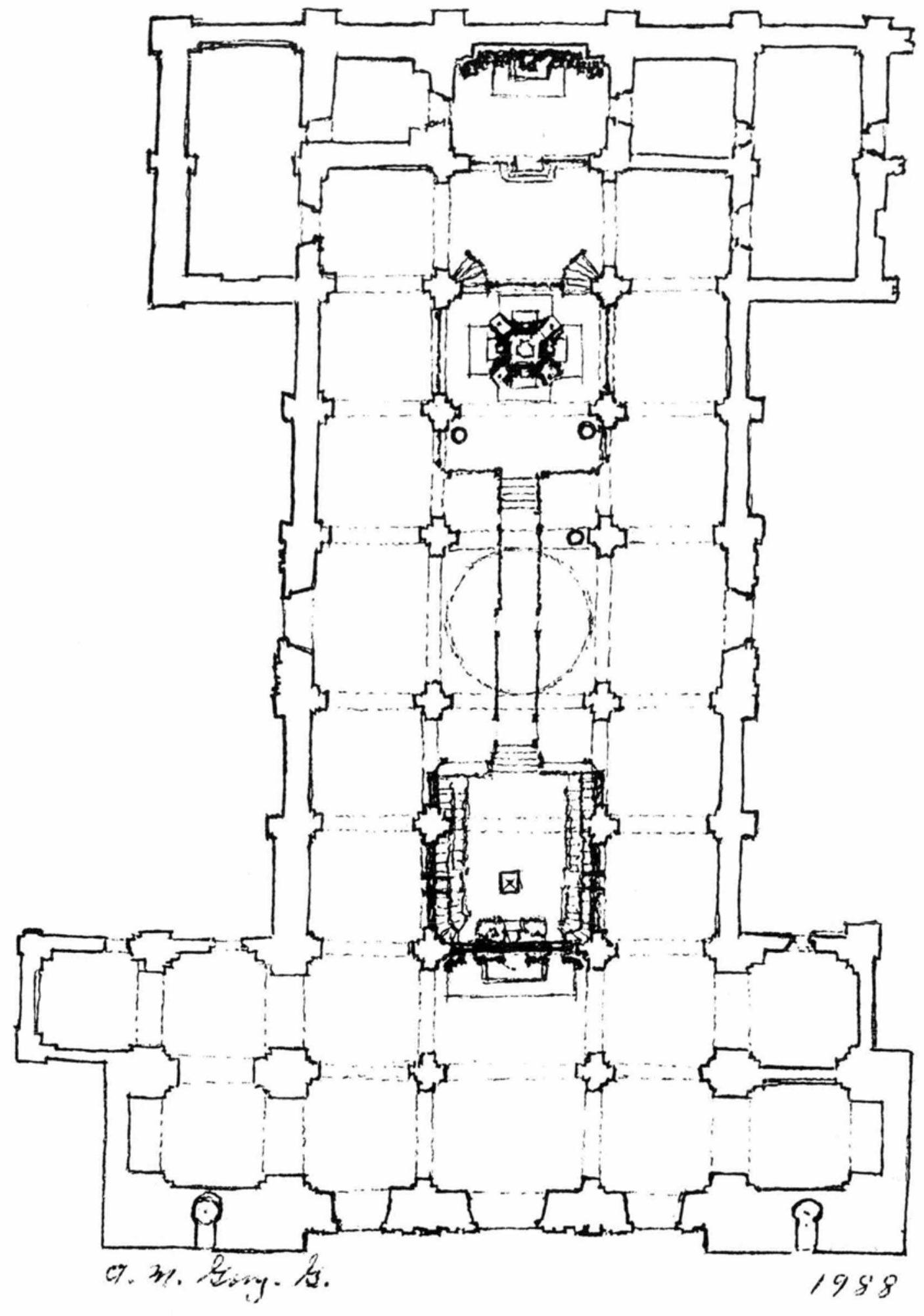


Lámina 4. Colocación supuesta, en planta y alzado, del ciprés barroco de la catedral de Valladolid (Morelia), Michoacán. Otra incógnita derivada de la glosa ofrecida para el documento descriptivo, consiste en preguntarse; pero... ¿en dónde se encontraba colocado con precisión el ciprés? Creemos que la respuesta más lógica es que se hallaba ubicado bajo la antepenúltima bóveda hacia el ábside y sobre la cripta que también se encuentra en este tramo, pues en el inventario de la joyería que poseía la catedral, levantado en 1787, la referencia al manifestador, (aún existente), y los cuatro frontales de plata que hubo, es que estaban; "en. el Panteón". Por otra parte no podía ser más que aquí, pues dada la disposición de la catedral, un tramo más atrás hubiera ocupado el que corresponde a la circulación del deambulatorio que unía sacristía, sala capitular y naves laterales, lo que para la época no hubiera sido permisible. Y, si un tramo más hacia adelante, hubiera estrechado demasiado el espacio entre coro y presbiterio quedando tan solo el tramo de la cúpula libre, lo que hubiera sido insuficiente. También es de suponerse que, por razones de aprecio visual y visibilidad, se encontraba el centro del tramo entre los cuatro grandes pilares para que así pudiera apreciarse libre su volumetría enmarcada por los arcos, lo mismo que las cuatro fachadas y frontales de altar para las celebraciones litúrgicas. Asimismo debemos considerar que, si la altura del ciprés era de 16 varas, o sean unos 13.36 metros, y las pilastras de la nave mayor alcanzan en la catedral los 14.80 metros desde el piso, aumentándole al ciprés 1 metro, que sería la altura aproximada del presbiterio original, nos darían unos 14.36 metros, lo que sensiblemente es la altura de las pilastras y, por tanto, el punto de trazo y arranque de los arcos, lo que acentuaría una armónica relación entre las dimensiones del ciprés con las proporciones de la nave central y todos los espacios con sus ángulos visuales, del interior del templo.

Croquis esquemático a escala. Proposición y dibujo de Manuel González Galván. 


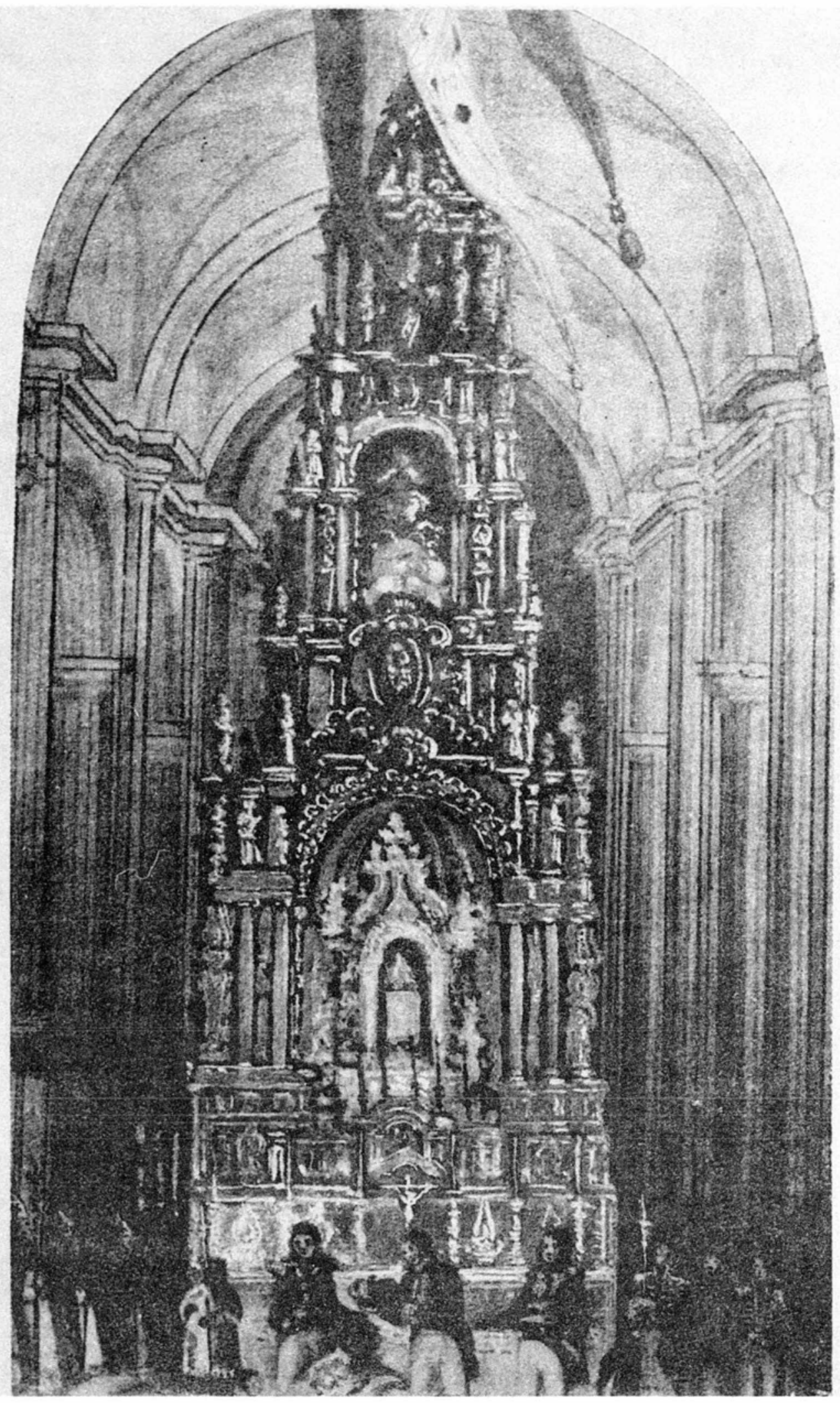


Figura 1. Antiguo ciprés barroco, (desaparecido), de la catedral de México, obra de Jerónimo de Balbás, siglo XVIII. Como puede apreciarse, hay similitud y coincidencia entre esta obra metropolitana y la vallisoletana, lo que se desprende de la glosa e interpretación del documento presentado por Isidoro Vicente. Es natural y consecuente que la obra del padre influya en la del hijo y así ambos se afilian estilísticamente a la modalidad del barroco estípite o churrigueresco. Ambos cipreses, también se componen de dos "camarines" y un remate. El primer cuadro contiene el "Torreón" o manifestador de plata para colocar el Santísimo y el segundo la imagen del patrocinio, con un final de exaltación hagiográfica religiosa, más numerosas esculturas y tan abundante como rica decoración complementaria.

Tomado de una pintura anónima que representa la Coronación de Iturbide en la catedral de México, 1822. Fototeca IIE. 


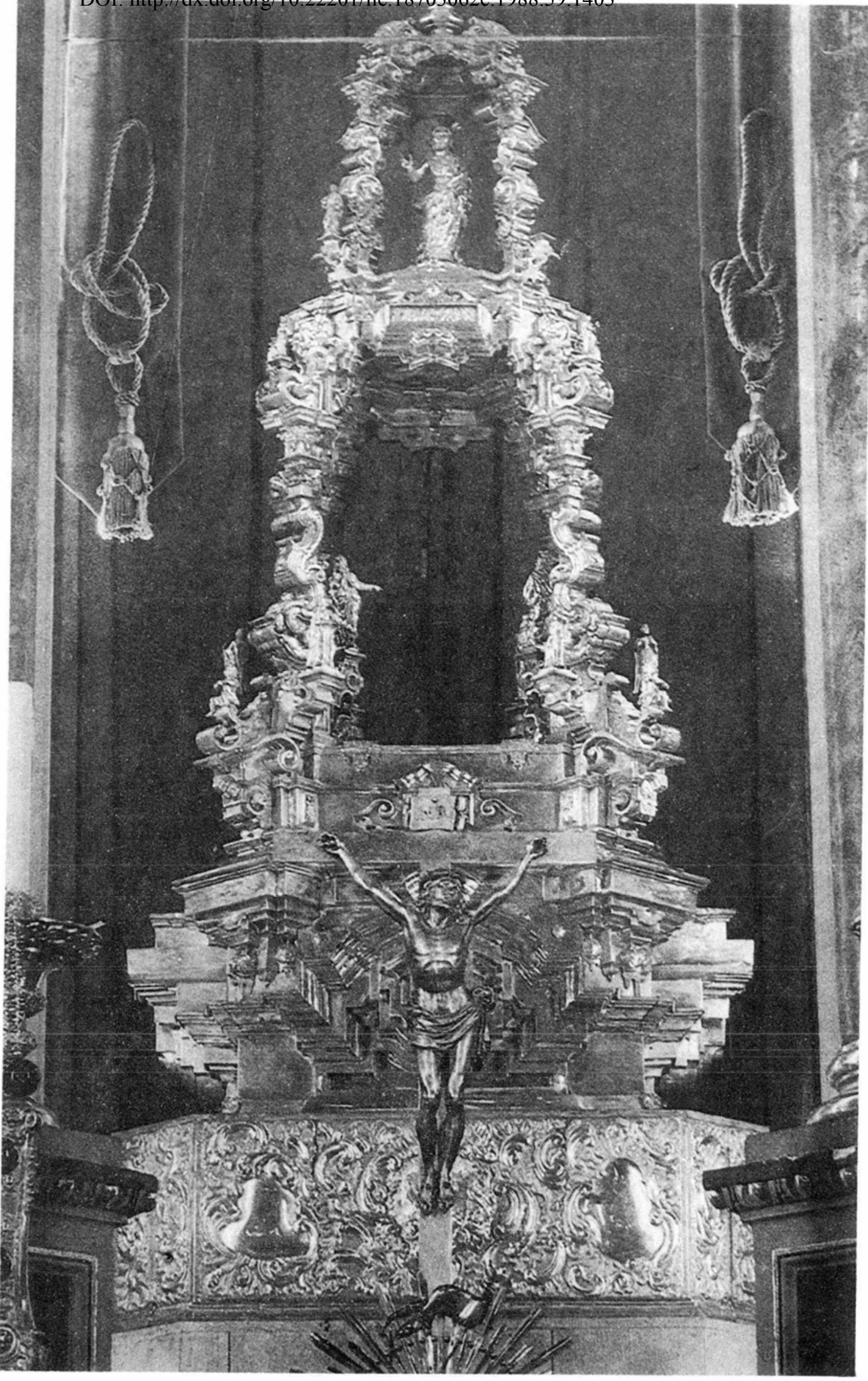


Figura 2. Manifestador de plata de la catedral de Morelia. Esta suntuosa y monumental joya de orfebrería barroca, es el único gran resto que aún puede admirarse del antiguo esplendor y riqueza del Templo. Mide 3.19 metros de altura y contiene 29 estatuillas y 42 relieves sobredorados que, por medio de una elaborada iconología, exaltan la presencia eucarística del Redentor. Es de hacerse notar la semejanza formal que este "Torreón" tiene con los cipreses de su tiempo y especialmente con el que debió contenerlo, con sus dos cuerpos o camarines; el principal abajo para colocar la custodia y el segundo para la imagen patronal. El manifestador estuvo complementado, y todo el ciprés se enriquecía, con cuatro frontales también de plata que el inventario de 1787 cita diciendo: Ytem "quatro frontales sobredorados que según apunte antiguo tienen quinientos marcos. Y son los mismos que sirven a las quatro mezas del Panteón". Foto: José Antonio Romo Careaga. 


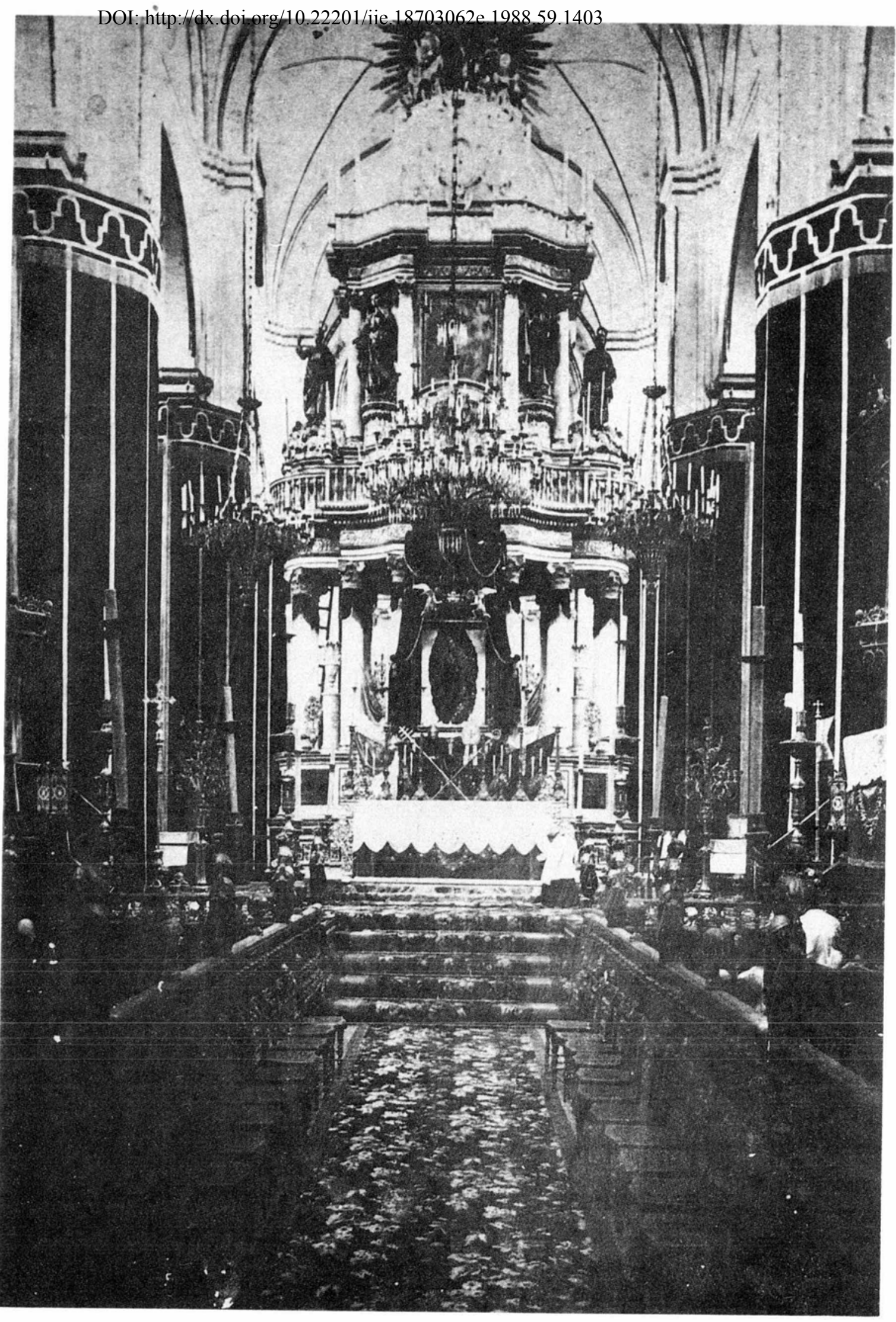


Figura 3. Ciprés neoclásico de la catedral de Morelia durante la segunda mitad del siglo XIX. Obra atribuible al arquitecto de origen italiano Zápari. Como puede observarse, este ciprés pertenece a la corriente de intención neoclásica que se manifestó entre nosotros al mediar el siglo XIX, pero con rasgos de abarrocamiento europeizante. Justamente, por 1848 , el cabildo de la catedral moreliana se dio a la tarea de sustituir todos los retablos barrocos, que fueron unos veinte según registra el inventario de 1787, por otros de carácter neoclásico. Medio siglo escaso a su vez sobrevivió la presente obra, pues al finalizar el siglo e iniciarse el presente, con la última y actual remodelación y decoración, a su vez desapareció el ciprés decimonónico, el coro en medio de la nave mayor, la crujía, el retablo de los Reyes neoclásico y algunos otros retablos de las naves laterales. Al parecer, la iconografía de éste ciprés mostraba en el segundo cuerpo a los cuatro evangelistas con San Pedro y San Pablo, todos en escultura y, como remate, La transfiguración de Cristo por ser el patrocinio del Templo.

Foto tomada el 12 de octubre de 1898. Fotografía de una foto antigua. Fototeca IIE. 


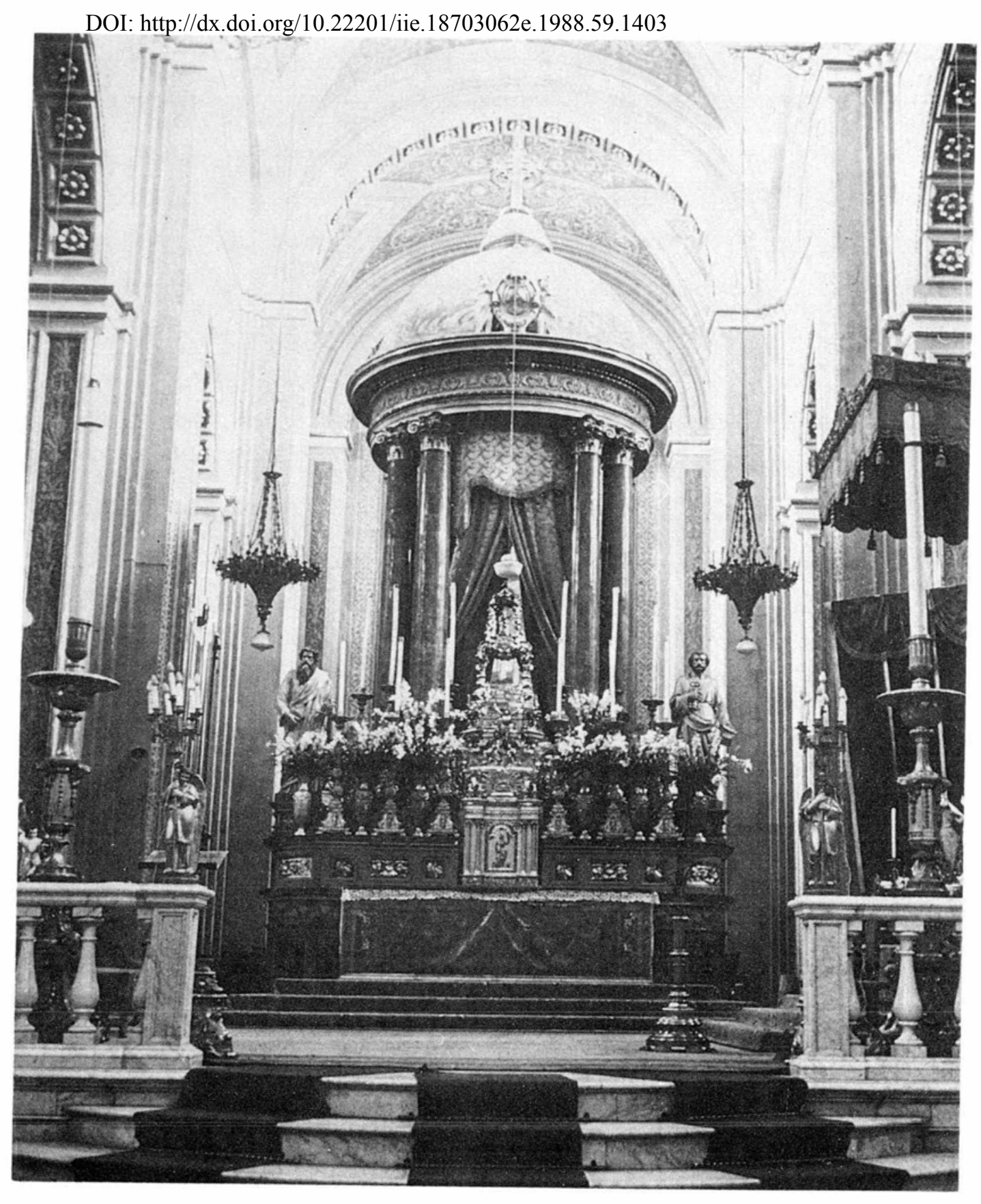

Figura 4. Ciprés actual de la catedral de Morelia, con el manifestador barroco del siglo XVIII y sagrario neoclásico de plata del XIX. El empobrecimiento del Templo ha ido de mal en peor, especialmente en lo que se refiere a la pérdida de obras de arte o sustitución de ellas por obras y objetos de menor valía, como puede comprobarse en la secuencia de los cambios del ciprés.

Foto: Elisa Vargas Lugo. Fototeca IIE. 
atrevemos a proponer una solución que resuelva la confusa relación de las cuatro puertas con las subidas angulares que corresponderían, a su vez, en número de cuatro y quizá dispuestas más bien como escaleras marinas o de mano, puesto que se especifica la ausencia de "peralte alguno de escalones". ¿O habría alguna fórmula de rampa? De cualquier manera la real solución de la planta es la incógnita más difícil de comprender o resolver, por lo que aquí simplemente la ponemos como hipótesis aproximada (lám. 2).

${ }^{3}$ La referencia a pabellones o cortinajes en el esplendor churrigueresco es casi imprescindible, pues otorgaban color, suntuosidad, teatralidad y movimiento a las obras, a más de que en la obra de los Balbás, este elemento siempre está presente, no obstante se deja al criterio del cabildo contratante la resolución final pues con un sentido práctico, que aún puede hasta sacrificar lo estético, "en caso de oscurecer sus interiores podrán omitirse o elevarse para estorbar esta reflexión", pues no debemos olvidar que en aquellos tiempos no había luz eléctrica y hubiera sido peligroso y difícil introducir en los estrechos y elevados camarines luz de velas.

${ }^{4}$ Lo de los cuatro estípites grandes en el retablo de los Reyes en Valladolid, al que se ha supuesto se refiere el documento que tratamos, ha hecho que también se le relacione, obviamente, con la obra de su padre Jerónimo en el retablo de los Reyes de México que justamente por los cuatro enormes estípites se distingue pero, aunque no aceptemos tal referencia por equívoca, la relación con las obras del padre y la derivación de ellas sin embargo, no se invalida, sino que se confirma cuando nos remitimos a la información que tenemos del también desaparecido ciprés de la catedral metropolitana (véase fig. 1).

En este ciprés hubo cuatro grandes estípites angulares rematados con esculturas y se mostraban en chaflán o a cuarenta y cinco grados, para mayor armonía angular, y que las esculturas no ofrecieran sus frentes en forma irregular sino radial. Así debió presentar sus estípites Isidoro en Valladolid y en eso nos basamos para suponerlos con esta colocación en nuestra reconstrucción ideal.

Desde luego que los cuatro doctores de remate que se proponen son: San Gregorio papa y San Jerónimo cardenal, con San Ambrosio y San Agustín obispos. Hasta es posible deducir que, conforme al orden jerárquico iconográfico correcto, a San Gregorio le correspondía; al frente, el ángulo derecho del ciprés, a San Jerónimo el izquierdo con San Ambrosio y San Agustín indistintamente en la parte posterior.

Mas no sabemos si fueron estos santos $\mathfrak{u}$ otros los que estuvieron por voluntad del "venerable señor deán y cabildo". 
${ }^{5}$ Este párrafo largo, abigarrado y complicado, es buena prueba del barroquismo formal y verbal de la época, no obstante intentemos desentrañar su urdimbre.

El primer camerín es el inmediato superior al altar correspondiendo a él la colocación del Manifestador del Santísimo en forma por demás similar al de México (véase lám. 2, y fig. 1).

Los cuatro arcos son los de cada una de las caras, y las ocho impostas responden al par de ellas que cada arco requiere en sus dos arranques, a la vez apoyadas en las respectivas "coronaciones" o remates estructurales de ocho estípites menöres que "guarnecen", o sea que enmarcan, delimitan y refuerzan, "el empilastrado de sus muros", lo que equivale a considerar que había unas traspilastras adosadas a la estructura. Encima ocho frontis, sin duda correspondiendo con el eje de los ocho estípites, sobre el "banquillo de dichas cornisas", lo que equivale a la presencia de pequeños apoyos como pedestales sobre el entablamento para recibir dichos frontis a su vez "adornados cada uno con dos reinos", o ángeles portando "atributos o insignias de cada uno de los santos patriarcas que en dicho lugar se ven figurados". Estos, por lo tanto, debieron ser ocho y sin duda representaban, en alto relieve, la imagen de grandes santos fundadores de órdenes religiosas, como era frecuente hacerlo dentro de la iconografía de la época. En tanto, lo que, "los cuales van opuestos a los arbotantes que se gozan por sus lados", no es muy claro, pero quizá sea una referencia a los propios estípites angulares girados cuarenta y cinco grados diagonalmente y que estos patriarcas hayan girado a su vez, unciosamente, hacia el sitio de colocación del Santísimo al centro del ciprés.

"En estas líneas entendemos que el "bastante follaje y gustosa talla" iba en aumento mientras "correlativamente" se disminuía, "especialmente en la formación de sus ocho medios estípites que se hallan inmediatos al segundo camarín de El Salvador", lo que indica que aquí los estípites ya no son exentos, sino medias muestras enmarcando por pares los cuatro arcos del camarín del Salvador, patrocinio cristológico primigenio del obispado de Michoacán. "Éstos están adornados con medallas, serafines y cortejos de caprichosa idea".

Así, tales estípites ya en disminución y repliegue debieron ser no obstante muy ricos en diseño y configurar el segundo camarín con volumetría ochavada.

${ }^{7}$ El párrafo se dedica a consignar las presencias escultóricas en relación con estos últimos estípites. "Al pie de los dichos están en cada uno de ellos, dos mancebos"; por lo tanto eran dieciséis, seguramente sentados en el cornisuelo de los pedestales y portando haces de espigas doradas 
"alusivas al divino sacramento", lo que nos demuestra una conciencia alegórica en la iconografía y las imágenes, lo que se reitera al anotarse como, "sobre las coronaciones de los dichos se dejan ver los siete príncipes y para completar los ocho lugares se podrá colocar el santo ángel custodio".

No olvidemos que los mencionados "siete príncipes" son los arcángeles más venerados e invocados y que cada uno de ellos cumple una función de servicio a la divinidad simbolizada en su propio nombre, lo que no está aquí por demás también recordar a saber: Miguel, Gabriel, Rafael, Uriel, Jehudiel, Baraquiel y Salatiel.

Ahora que, como Balbás se está refiriendo a ocho "coronaciones", sugiere que "para completar los ocho lugares se podrá colocar el santo ángel custodio". Interesantes líneas pues de ellas podemos deducir, confirmando, que el cuerpo del segundo camarín era ochavado.

Pero lo más importante es como que se ha supuesto, consistente en que no sólo teólogos o mecenas de obras religiosas dictaban la iconografía, si no que en ocasiones el mismo arquitecto o proyectista la proponía, queda consignado y verificado en varios documentos; como es el caso.

${ }^{8} \mathrm{El}$ remate, según el párrafo, "adornado con la misma fachada que muestra su delineảción", aunque ochavado, indicaba seguir las líneas de composición generales, ofreciendo a cada una de las cuatro caras mayores, "una graciosa tarjeta" o tarja para alojar en ellas, al frente, "las armas de san Pedro"; tiara y llaves, mientras en las tres similares o "de su mismo tenor", las de la Iglesia, quizá aquí refiriéndose a las episcopales de mitra y báculo - las que en especial "parezcan más del agrado del venerable señor deán y cabildo". Aquí también se mencionan las últimas esculturas del remate: "el triunfo de la fe, con el acompañado de ocho ángeles con palmas y ramos de oliva". Las palmas y ramos de oliva símbolos justamente triunfalistas, en tanto la figura de la Fé, como centro y culminación, debió tener los consabidos símbolos que la identifican; una figura femenina con el rostro vendado, caliz con ostia en su mano derecha y cruz en la izquierda.

"Los cuatro "depósitos" que se mencionan, son los cuatro sagrarios para depositar el Santísimo, acompañados de cuatro altares inherentes a los llamados cipreses, lo que vuelve a confirmar que la descripción y proyecto a éste se refería.

Los frontales de los altares y los sagrarios era de lo que se hacía con más cuidado y riqueza, por lo que es elocuente la frase de Balbás que omite "relacionarlos" o relatarlos y remite a los señores del cabildo a que los juzguen en el plano del proyecto, "por lo muy patente que se dejan ver 
en su delineación, pues en él se muestra lo claro, vistoso y agradable de su construcción".

${ }^{10}$ Finalmente, con cierto desenfado o tono desinteresado por el aspecto económico material y de honorarios, establece que en lo que se refiere a precio, y aunque en lo escrito diga "aprecio", no hay la intención de valoramiento que implica el verbo apreciar, sino de consideración económica, lo cual queda muy claro si se releen los últimos renglones, donde Isidoro apunta: "me remito a la exposición que tengo presentada", es de suponerse que "la exposición" no es más que un presupuesto, el que como siempre ha sucedido, y sigue sucediendo, en este punto con cautela profesional continúa: "dudando el manejo que pueda haber en esa ciudad con los operarios y costos de maderas, el que una vez informado de todo, haré lo que sea del agrado de dichos señores sin ningún perjuicio mío. Por tanto lo firmé". 